Resenha do livro:

SOUZA, Ricardo Luiz de. Identidade Nacional e Modernidade brasileira: o diálogo entre Sílvio Romero, Euclides da Cunha, Câmara Cascudo e Gilberto Freyre/ Ricardo Luiz de Souza. Belo Horizonte: Autêntica, 2007. 232 p.

Resenha por:

Daniela Perpétua de Andrade

danielasjdr@yahoo.com.br

Universidade de São João del-Rei - UFSJ

\title{
A RELAÇÃO ENTRE CULTURA E IDENTIDADE NACIONAL
}

O autor do livro Identidade Nacional e Modernidade brasileira: o diálogo entre Sílvio Romero, Euclides da Cunha, Câmara Cascudo e Gilberto Freyre, Ricardo Luiz de Souza, é mestre em Sociologia e doutor em História pela Universidade Federal de Minas Gerais (UFMG). Atualmente, é professor do Centro Universitário de Sete Lagoas (UNIFEMM).

A publicação é resultado da tese de Doutorado defendida no Departamento de História da Universidade Federal de Minas Gerais no ano de 2006, sob a orientação de José Carlos Reis. Este livro volta-se para a compreensão de um conjunto de obras de estudiosos da cultura popular no Brasil. Identidade nacional, modernidade e tradição são os temas envolvidos por um diálogo indireto entre os quatro autores: Sílvio Romero, Euclides da Cunha, Câmara Cascudo e Gilberto Freyre.

Trata-se de obras preocupadas em fornecer grandes interpretações do Brasil, esforço que possibilitaria o desenvolvimento da lógica que as perpassa. Ao se debruçar sobre o pensamento desses autores, Souza analisa a chamada "questão nacional" e o conceito do que é ser brasileiro, elementos que identificam o povo e os diferenciam de outras nações. No entanto, num esforço de análise assim conduzido, deve haver cuidado a fim de não submeter o que uma obra tem de característico.

Na cultura brasileira, a definição de identidade nacional foi um tema de debate crucial. A relação entre tradição e modernidade constituiu o tema central no debate sobre a formação, desenvolvimento e futuro da nacionalidade.

Souza recupera a discussão sobre Modernidade e Identidade Nacional. Este autor é sagaz ao problematizar a identidade nacional, apontando sua presença em relações de poder, interação com as outras nações, construção como discurso, dinâmica e heterogeneidade. Esse debate é analisado tomando como eixo questões como o que é ser brasileiros, elementos da brasilidade que nos identificam como povo e nos diferenciam das outras nações, processos da formação da nacionalidade brasileira e a formação racial dos brasileiros. Além dessas questões, Souza trata de como se deu, tem se dado, e deve se dar a relação entre tradição e modernidade, assim como a possibilidade de conciliação da identidade nacional e modernidade. $\mathrm{O}$ autor elucida essas e outras questões ao refletir sobre a obra desses autores e também ao contemplar o processo histórico vivido e ainda vivenciado pelo Brasil.

A identidade nacional e a relação entre tradição e modernidade, constituem temas presentes nas obras dos autores abordados. Em um primeiro momento, o autor toma cuidado em definir esses conceitos e apóia-se em autores como Nobert Elias (1990) e Garcia Canclini 
(1997). Para Nobert Elias, a identidade é subjacente aos povos e moldada por regularidades humanas e sociais. Garcia Canclini explica que a incerteza em relação ao sentido e ao valor da modernidade deriva não apenas do que separa nações, etnias e classes, mas também dos cruzamentos socioculturais em que o tradicional e o moderno se misturam. Esta identidade nacional inspirada no conceito de "memória coletiva" de Halbwachs (1990) seria estruturada pela tradição.

A identidade nacional ligada a valores compartilhados e vinculada a países fundadores que as encarnam como símbolo de um passado a ser reverenciado. Já a tradição é corporificada em símbolos que a representam. A modernidade é definida pelo seu caráter aberto e conectada a uma permanente transformação. Para o autor, os debates sobre a formação ou existência de uma identidade nacional e sobre a relação entre tradição e modernidade não podem ser compreendidos de forma isolada (SOUZA, 2007). .

Sílvio Romero foi o primeiro autor a ser abordado pela sua preeminência em termos da sistematização sobre a identidade nacional e pelo caráter pioneiro e inovador de sua obra. Esse autor privilegia temas como: identidade nacional, cultura popular e raça. A cultura popular serve como instrumento indispensável de análise e compreensão da identidade nacional. Ele chama atenção para a compreensão do processo de formação racial do brasileiro e, mais especificamente, a importância da miscigenação como elemento central desse processo, o que torna indispensável para compreendermos a construção e os sentidos adquiridos pela identidade nacional. Ainda de acordo com Romero (1997), a modernização é travada pelas condições socioeconômicas, campo e cidade, província e corte. Segundo ele, também seria preciso superar a imitação de modismos importados e a macaqueação do estrangeiro, especialmente o francesismo.

Na perspectiva de Romero (1969), a modernização brasileira é travada pelas condições socioeconômicas do País; uma nação embrionária que tem em uma lavoura rudimentar sua principal fonte de riquezas, sem classe operária, toda ela marcada pela inércia, com pequenas indústrias locais e uma malha urbana rarefeita, com uma população caracterizada pela passividade e uma classe média pouco significante. Eis o quadro descrito por ele, do qual parte para pensar a questão da modernidade.

Romero ao analisar a obra de Euclides da Cunha aponta algumas contradições que também são as suas. Ambos adotam uma dualidade elite versus nação, na qual aquela é responsabilizada por ignorar esta e tentar construir um mundo a parte feita de materiais de empréstimo.

Romero aponta em suas análises que os caminhos adotados para a modernidade no Brasil geraram uma nação injusta e excludente. A formação da nacionalidade brasileira constituiu-se não apenas por miscigenação racial, que também deveria ser completada pelo branqueamento, mas também sociocultural. Então, sua obra é uma demonstração das razões de seu pessimismo.

O segundo autor a ser abordado por Souza (2007) é Euclides da Cunha. Euclides tinha um olhar tanto de engenheiro como de literato observador. Seu pensamento era estruturado pelo encontro de duas temáticas: a modernidade e a identidade nacional, a civilização e o sertão. Ele ao observar Canudos assinala como fatores explicativos do Brasil elementos genéticos, sociais e físicos. Souza cita Levine (1995) que explica a base e o sentido do conflito não apenas em termos humanos, como também a partir da história geomorfológica, climática e demográfica da região. Euclides ao observar Canudos, formula o núcleo de suas criticas às elites e critica a alienação deste grupo. 
Para Euclides o atraso do sertanejo não se deve basicamente sua inferioridade racial. A culpa recai sobre as elites que não tem olhos para o sertão e o condena ao mais completo abandono. Sua obra, Os Sertões, deve ser entendida não apenas no sentido geográfico da palavra, simbolizando também, um tempo anterior à modernidade, que ultrapassa qualquer espaço fisicamente bem determinado e bem demarcado pelo autor como um tempo sertanejo que desaparece. Revela a existência de dois brasis: um progressista nas cidades do litoral e outro arcaico do interior, no sertão. Contrapõe o mulato do litoral (complacente) ao mestiço do interior (rígido)

O mestiço e o sertanejo são para Euclides da Cunha seres distintos; as teorias que condenam o mestiço como ser inferior e degradado não valem para o sertanejo. Para Euclides e Romero, o processo de formação da nacionalidade funciona como obstáculo a ser vencido no que tange aos projetos de nacionalidade por eles delineados. Trata-se de superar a desvantagem resultante de uma formação social e racial mestiça por meio da ação pedagógica das elites, de forma a incorporar os novos padrões de civilização a toda uma população que foi deixada a margem.

O terceiro autor a ser abordado é Câmara Cascudo. Para ele, aparece a dicotomia entre sertão e cidade, assim como, província e centro urbano. Cascudo tem a pretensão de preservar a cultura popular a partir da qual, se poderia vislumbrar a identidade nacional. Para Cascudo, o povo é produtor de uma cultura e as elites cabem o domínio político e as posições de mando na hierarquia social. A obra de Cascudo é centrada em uma perspectiva elitista e o povo é apontado como figurante, mas é exaltado como produtor de cultura. Cascudo (1984) entende que o conto popular revela informação histórica, etnográfica, sociológica, jurídica e social. É um documento vivo, apontando costumes, ideias, mentalidades, decisões e julgamentos.

Tendo em vista que os primeiros estudos estavam preocupados com a interpretação da sociedade brasileira, na sua grande maioria, apresentaram tendência culturalista, primando pela cultura como aspecto privilegiado para o entendimento da realidade social. Câmara Cascudo, um dos mais conhecidos folcloristas do país, etnógrafo que se limitou basicamente ao registro de fatos, descreveu contos e lendas, elaborando fontes para a investigação da cultura popular. Suas elaborações ocorreram fora do espaço acadêmico, por isso não é considerada estritamente um cientista social, porém um respeitado estudioso da cultura popular. Dessa maneira, justifica-se escolha acertada desse autor por Souza.

O último autor a ser abordado é Gilberto Freyre, sociólogo nordestino que utiliza o conceito de cultura para entender a realidade brasileira. Freyre desmoraliza cientificamente o racismo com suas obras Casa Grande e Senzala (1933), Sobrados e Mucambos (1936) e Nordeste (1937).

Tanto em Cascudo quanto Freyre, a miscigenação atua como fator contrário ao surgimento de preconceitos, como fator democratizante e como instrumento de consolidação de uma sociedade racialmente harmoniosa. Cascudo valoriza o povo enquanto criador de tradições cuja preservação, contudo, cabe mais às elites que a ele próprio, devendo agir este como tutor daquele. Na obra de Cascudo, o sertão é situado como espaço geográfico oposto aos grandes centros urbanos e como temporalidade oposta à modernidade, lugar de tradição, espaço onde se configurou uma identidade nacional e sertaneja.

Gilberto Freyre, por sua vez é um continuador do pensamento tradicional, estudioso que privilegiou a problemática cultural. Assim como Cascudo, não apenas ressalta a existência da identidade nacional, como faz sua defesa ao mesmo tempo em que sublinham o risco de seu desaparecimento sob o impacto da modernidade. Este autor estruturou sua obra na descrição 
da modernização e também na nostalgia por um passado muitas vezes definido como idilicamente comunitário e qual se enraíza a identidade nacional. Câmara Cascudo entendeu a modernidade como horizonte inescapável.

Souza destaca que o otimismo Freyreano em relação ao futuro assenta-se na defesa que faz da mestiçagem, pois é ela que define a identidade nacional brasileira, o que possibilitaria uma vantagem num mundo pós-moderno. Da automação decorreria um tempo livre para o qual a vivência hispânica do tempo estaria mais preparada. Ao contrário dos outros autores, em Freyre a modernidade é superada, pois se trata de um momento histórico no qual uma série de valores urbanos entraria em conflito com um sistema rural no qual os contrários se equilibrariam.

Considerando o diálogo entre Euclides da Cunha, Sílvio Romero e Gilberto Freyre, a relação entre tradição e modernidade segundo a miscigenação torna-se hipótese para a criação de uma raça brasileira. O passado preciso ser preservado da modernidade, ele e todo seu acompanhamento de hábitos, crenças e tradições.

$\mathrm{O}$ debate sobre modernidade e identidade nacional se articula em Freyre partindo de questões básicas como a relação entre a arte e ciência. Freire (1962) explica se alguém acrescenta ao seu conhecimento da antropologia ou às suas analises de historia ou de sociologia um poder literário de expressão, então terá conseguido combinação ideal.

Ainda de acordo com Freyre (1967) não há ciência mais dependente de outras ciências que a sociologia. O olhar de Freyre sociólogo e historiador eram inseparáveis. Tanto em Cascudo quanto em Freyre, a miscigenação atua como fator contrário ao surgimento de preconceitos, como fator democratizante e como instrumento de consolidação de uma sociedade racialmente harmoniosa.

Souza menciona Ricardo Araujo (1994), em seu livro, ao explicar que o conceito de raça é auxiliar no método de Freyre. Ele utiliza-o como se não quisesse se comprometer com seu sentido usual. Antagonismos insuperados e insuperáveis que fundamentariam a sociedade brasileira, sertão e litoral para Euclides. Casa-grande e senzala, sobrado e mucambo, ordem e progresso, são antagonismos resolvendo-se na obra de Freyre em uma nação cujas promessas são a mestiçagem e a conciliação.

Nas obras de Sílvio Romero, Euclides da Cunha, Gilberto Freyre e Câmara Cascudo, apresenta-se um diálogo de buscas de respostas para um projeto de nacionalidade. Estes autores buscaram defender dos avanços da modernidade a tradição preservada e refugiada na província. Eles interrogaram e procuraram o processo de formação nacional em busca de suas linhas evolutivas, de seu sentido, de suas consequências para o presente e o futuro.

Souza repete nas conclusões sobre os quatro autores que estudou o peso de uma análise biográfico-sociológica. Chama as "origens sociais" daqueles pensadores, salientando, em Câmara Cascudo e Gilberto Freyre, serem "descendentes de elites rurais provincianas em pleno processo de decadência e perda de poder a nível político e econômico". Sylvio Romero foi identificado a uma "classe média nordestina empobrecida" e Euclides da Cunha ligado à "pequena burguesia urbana".

Souza tem o mérito de tratar de fatores relacionados aos conceitos que coloca em destaque. Seu estilo, marcado por uma análise que privilegia um grande número de aspectos, colocados nos parágrafos, possibilita tal feito, além de tornar o texto mais interessante pela ampla e variada instrução que demonstra, e não por uma redundância que rejeita.

Ao retratar os conceitos de "identidade nacional", "modernidade" e "tradição" nas obras selecionadas, cuja importância da análise é por sinal muito bem fundamentado, Souza 
enfrenta deste modo, a produção discursiva de maneira muito acertada. Não há, conforme se depreende desta leitura, um discurso unitário, definitivamente hegemônico, sobre o que viria a ser a identidade do brasileiro.

O que se verifica, em contraposição, é uma constante disputa por definições, cada uma delas ajeitando de maneira específica e em variados graus de sucesso um "estoque" disponível para as mais variadas interiorizações individuais. Desta forma, embora constantemente se afirme que o poder público impôs uma unificação cultural por intermédio de uma definição específica do que fosse a identidade nacional, pode-se perceber que esta realidade discursiva é muito mais complexa e não deve ser encarada como um único discurso vencedor.

No entanto, num esforço de análise assim conduzido, marcado por uma análise que privilegia vários aspectos, colocados em parágrafos relativamente curtos e abundantes.

\section{Referências}

ARAÚJO, Ricardo Benzaquem. Guerra e paz; Casa grande e Senzala e a obra de Gilberto Freyre nos anos 30. Rio de Janeiro: Editora 34, 1994.

CANCLINI, Néstor Garcia.Culturas hibridas: estratégias para entrar e sair da modernidade . São Paulo : Edusp, 1997.

CASCUDO, Luis da Camara. Literatura oral no Brasil. Belo Horizonte/ São Paulo : Itatiaia/EDUSP, 1984.

CUNHA, Euclides da. À margem da história. São Paulo : Edusp, 1995.

ELIAS, Nobert. O processo civilizatório. LISBOA : Publicaçoes Dom, 1990.

Freyre, Gilberto. Casa grande e senzala. Brasilia .Rio de Janeiro: José Olympio,1978

GILBERTO, Freire. Homen, Cultura e tropico . Recife : Imprensa Universitaria , 1962a.

FREYRE, Gilberto. Sociologia. Rio de Janeiro: José Olimpio, 1967

LEVINE, Robert M. O sertão prometido: O massacre de Canudos. São Paulo : Edusp, 1995.

HALBWACHS, Maurice. A memória coletiva. São Paulo: Vértice, 1990. 189 p.

ROMERO, Silvio. 1977. Estudos sobre a poesia popular no Brasil. Petropolis : Vozes, 1977.

ROMERO, Sílvio. Obra filosofica. Rio de Janeiro : Jose Olympio, 1969. 